\title{
effectiveness and results
}

\begin{abstract}
Purpose To evaluate the indications and results of inverse Knapp procedures performed at one institution over a 10 year period between 1987 and 1996.

Methods The records of patients who had undergone inverse Knapp procedures were retrospectively reviewed. Demographic data were collected, pre- and post-operative orthoptic assessments were evaluated, and pre- and post-operative binocular single vision (BSV) charts and Hess charts were scored. Results Twenty-one patients were identified and records were available in 17 . The main indication for the operation was orbital trauma. The mean vertical deviation in primary position and downgaze improved from 16.06 prism dioptres (PD) to 7.35 PD and

Cooper and Greenspan ${ }^{4}$ proposed the same principle but with transfer of the horizontal recti to the inferior rectus insertion for the treatment of congenital depression deficiency. Dunlap ${ }^{5}$ advocated the same procedure for the treatment of double depressor underaction. This procedure is now commonly described as the inverse Knapp procedure.

The inverse Knapp procedure is used for the treatment of double depressor palsy and congenital or acquired inferior rectus deficiency. ${ }^{6-8}$ Others have reported good results with a recess/resect procedure in the treatment of inferior rectus weakness. ${ }^{9}$ Little has been published on the indications, effectiveness and results with the inverse Knapp procedure. We present a retrospective review of patients who underwent this operation at our institution.
\end{abstract} 26.45 PD to 6.66 PD respectively. The preoperative average score for BSV was $42 \%$, increasing to $62 \%$ post-operatively. The Hess chart error scores improved on average from $\mathbf{8 4 8 . 8}$ pre-operatively to $\mathbf{2 9 6 . 4}$ post-operatively. Further operations were required for 8 patients.

Conclusions Inverse Knapp procedure is an uncommon strabismus operation but an extremely useful one in selected cases. We recommend it for the treatment of marked inferior rectus weakness, congenital or acquired, for post-traumatic inferior rectus underaction with or without orbital blow-out fracture and for residual large hypertropia in patients with poor binocular functions. The extent of inferior rectus underaction should be assessed very carefully to avoid overcorrecting.

Key words Effectiveness, Inferior rectus paralysis, Inverse Knapp

Alvaro first suggested the management of vertical deviations with horizontal rectus surgery. ${ }^{1}$ Later Knapp described full transfer of the horizontal recti to the level of the superior rectus insertion for the treatment of double elevator palsy. ${ }^{2}$ This technique, which now bears his name, has since become an established treatment for elevation deficits. ${ }^{3}$

\section{Materials and methods}

Patients who underwent inverse Knapp procedures between January 1987 and December 1996 were identified. Age, sex, diagnosis, operation and follow-up period were obtained. The results of the pre-operative and post-operative orthoptic assessments were evaluated. All the patients underwent a prism cover test (PCT) with the prism bar in primary position and in downgaze for near and distance, and when necessary a PCT was performed in other gaze positions. An intraoperative traction test under general anaesthetic was performed in every patient. All the procedures were either supervised or performed by one of the authors (J.P.L.). All the inverse Knapp procedures consisted of full transfer of the horizontal recti in the affected eyes to the level of the inferior rectus with the cut end of the muscles lying along the spiral of Tillaux as shown in Fig. 1. In those patients who had had previous horizontal muscle surgery the distances between the limbus and the muscles were measured intraoperatively and were maintained after the transposition. No adjustable sutures were used.

Where available, pre- and post-operative binocular single vision (BSV) charts and Hess charts were scored according to the systems described by Woodruff et al. ${ }^{10}$ and Aylward

\section{Maurino \\ A.S.L. Kwan \\ J.P. Lee \\ Moorfields Eye Hospital London EC1V 2PD, UK \\ Mr John Lee \\ Strabismus Service \\ Moorfields Eye Hospital \\ City Road \\ London EC1V 2PD, UK}

Received: 7 January 2000 Accepted in revised form: 5 September 2000 


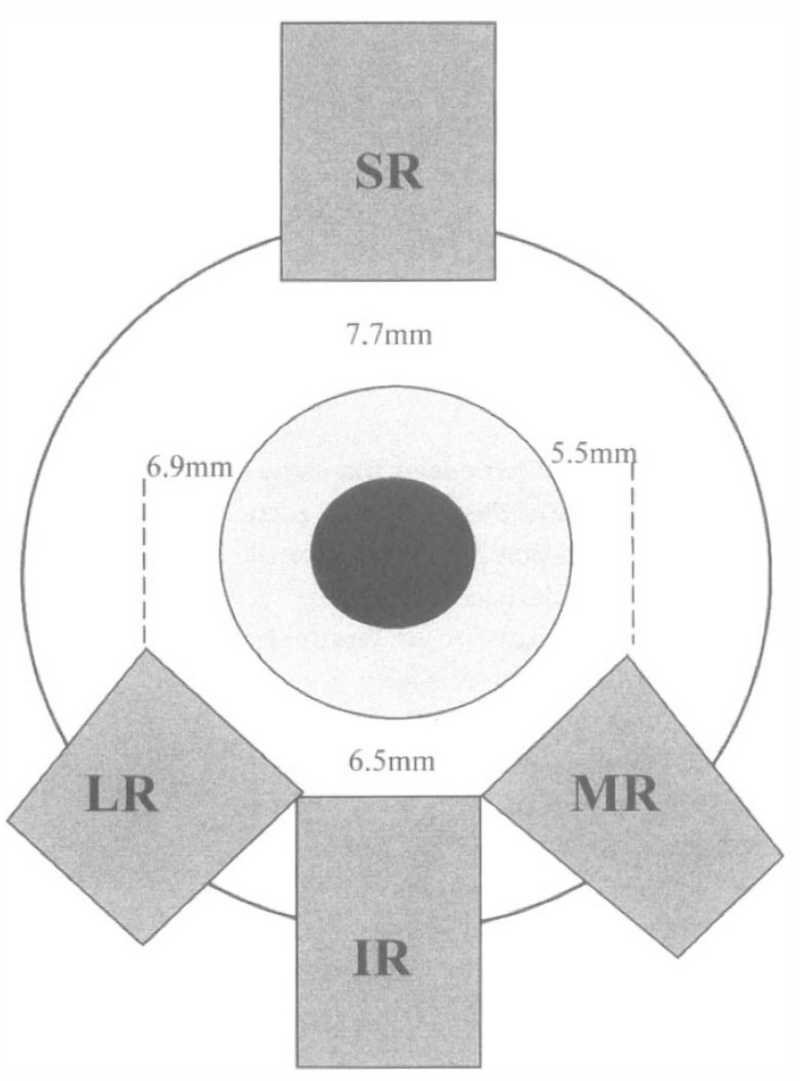

Fig. 1. The spiral of Tillaux. The insertions of the rectus muscles increase in distance from the limbus in the sequence medial, inferior, lateral and superior. The broken lines indicate the positions of the horizontal recti before the inverse Knapp procedure.

et al. ${ }^{11}$ All measurements were taken following the inverse Knapp procedure alone, and except for any overcorrected patient who had a further procedure the measurements refer to the final outcome.

\section{Results}

Twenty-one patients were identified and notes were available for 17. All had the inverse Knapp procedure alone, except one who also had contralateral inferior rectus recession and ipsilateral recess/resect of the horizontal recti for esotropia (patient 14, Table 1). The mean age was 30.4 years (range $5-75$ years). The male to female ratio was 2.4 to 1 . The mean follow-up period was 12.1 months.

Table 1 shows the clinical characteristics of the patients and their primary diagnoses. They are divided into three groups according to the primary diagnosis. Group 1 consists of 9 patients with a history of orbital trauma, 6 of whom had a documented blow-out orbital fracture and had undergone maxillofacial surgery to repair the bone defect. The rest had no evidence of orbital fracture and therefore the paresis of the inferior rectus could be related either to direct nerve or muscle injury or to fibrosis after pre-existing oedema and haemorrhage. In all patients the inverse Knapp procedure was undertaken at least 8 months following the orbital trauma or the orbital surgical repair. Group 2 includes 5 patients with a diagnosis of congenital or acquired inferior rectus weakness. Group 3 consists of 3 patients with residual hypertropia due to various aetiologies. They all had previous surgery and absent or very poor binocular function. The indication for the surgery was cosmetically poor residual hypertropia.

Table 2 compares the pre- and post-operative vertical deviation in primary position and downgaze. On average the mean vertical deviation (MVD) for all 17 patients in primary position and downgaze improved from 16.06 prism dioptres (PD) to 7.35 PD and from 24.65 PD to $6.66 \mathrm{PD}$ respectively. The most significant improvement

Table 1. Patient characteristics

\begin{tabular}{|c|c|c|c|c|c|c|c|}
\hline $\begin{array}{l}\text { Patient } \\
\text { no. }\end{array}$ & $\begin{array}{c}\text { Age } \\
\text { (years) }\end{array}$ & Sex & Diagnosis & Side & $\begin{array}{l}\text { Previous squint } \\
\text { operation }\end{array}$ & $\begin{array}{l}\text { Follow-up } \\
\text { (months }\end{array}$ & $\begin{array}{l}\text { Second } \\
\text { operation }\end{array}$ \\
\hline \multicolumn{8}{|c|}{ Group 1: orbital trauma } \\
\hline 1 & 75 & $\mathrm{M}$ & Blow-out & $\mathrm{L}$ & No & 10 & No \\
\hline 2 & 51 & $\mathrm{M}$ & Blow-out & $\mathrm{L}$ & No & 12 & Yes \\
\hline 3 & 43 & $\mathrm{M}$ & No blow-out & $\mathrm{R}$ & No & 9 & No \\
\hline 4 & 33 & $\mathrm{M}$ & Blow-out & $\mathrm{R}$ & No & 9 & No \\
\hline 5 & 18 & M & Blow-out & $\mathrm{L}$ & No & 18 & No \\
\hline 6 & 6 & M & Blow-out & $\mathrm{L}$ & No & 12 & No \\
\hline 7 & 60 & $\mathrm{~F}$ & Blow-out & $\mathrm{R}$ & No & 14 & No \\
\hline 8 & 16 & $\mathrm{~F}$ & No blow-out, associated exotropia & $\mathrm{R}$ & No & 12 & Yes \\
\hline 9 & 20 & M & No blow-out, associated exotropia & $\mathrm{R}$ & Yes & 10 & Yes \\
\hline \multicolumn{8}{|c|}{ Group 2: Inferior rectus underaction } \\
\hline 10 & 5 & $\mathrm{M}$ & Congenital & $\mathrm{L}$ & No & 11 & Yes \\
\hline 11 & 6 & $\mathrm{M}$ & Congenital & $\mathrm{L}$ & No & 6 & Yes \\
\hline 12 & 41 & $\mathrm{M}$ & Acquired, skew deviation following stroke & $\mathrm{L}$ & No & 12 & Yes \\
\hline 13 & 12 & $\mathrm{M}$ & Congenital & $\mathrm{L}$ & No & 12 & No \\
\hline 14 & 52 & $\mathrm{~F}$ & $\begin{array}{l}\text { Acquired, associated MR underaction, } \\
\text { ?3rd cranial nerve palsy }\end{array}$ & $\mathrm{L}$ & No & 10 & Yes \\
\hline \multicolumn{8}{|c|}{ Group 3: Other (residual hypertropia) } \\
\hline 15 & 9 & $\mathrm{~F}$ & Congenital esotropia, residual DVD & $\mathrm{L}$ & Yes & 28 & No \\
\hline 16 & 54 & M & Congenital esotropia, consecutive exotropia, $\mathrm{R} / \mathrm{L}$ & $\mathrm{R}$ & Yes & 12 & No \\
\hline 17 & 17 & $\mathrm{~F}$ & $\begin{array}{l}\mathrm{R} 4 \text { th cranial nerve palsy, numerous surgery, } \\
\text { residual } \mathrm{R} / \mathrm{L}\end{array}$ & $\mathrm{R}$ & Yes & 9 & Yes \\
\hline
\end{tabular}

$\mathrm{L}$, left; $\mathrm{R}$, right; DVD, dissociated vertical deviation; $\mathrm{R} / \mathrm{L}$, right over left; $\mathrm{MR}$, medial rectus. 
Table 2. Pre- and post-operative prism cover tests

\begin{tabular}{|c|c|c|c|c|c|c|}
\hline \multirow[b]{2}{*}{ Patient no. } & \multicolumn{3}{|c|}{ Pre-operative assessment } & \multicolumn{3}{|c|}{ Post-operative assessment } \\
\hline & AHP & PCT PP & PCT downgaze & AHP & РCT PP & PCT downgaze \\
\hline \multicolumn{7}{|c|}{ Group 1: Orbital trauma } \\
\hline 1 & Yes & 20 & 24 & No & 2 & 5 \\
\hline 2 & No & 24 & 30 & Yes & 16 & 20 \\
\hline 3 & No & 6 & 20 & No & 0 & 3 \\
\hline 4 & No & 10 & 14 & No & 3 & 6 \\
\hline 5 & Yes & 24 & 40 & No & 2 & 4 \\
\hline 6 & Yes & 22 & 33 & No & 4 & 6 \\
\hline 7 & Yes & 4 & 19 & No & 1 & 4 \\
\hline 8 & Yes & 16 & 24 & Yes & 5 & 5 \\
\hline 9 & No & 3 & 26 & No & 7 (Rev) & $2(\operatorname{Rev})$ \\
\hline MVD & & & 14.33 & 25.56 & 4.44 & 6.11 \\
\hline \multicolumn{7}{|c|}{ Group 2: Inferior rectus underaction } \\
\hline 10 & Yes & 15 & 17 & Yes & $30(\operatorname{Rev})$ & 30 (Rev) \\
\hline 11 & Yes & 12 & 23 & Yes (Rev) & 16 (Rev) & 18 (Rev) \\
\hline 12 & Yes & 16 & 18 & Yes & 8 & 4 \\
\hline 13 & No & 4 & 20 & No & 2 & 4 \\
\hline 14 & Yes & 40 & 40 & Yes & 5 & 10 \\
\hline MVD & & 17.40 & 23.60 & & 12.20 & 15.20 \\
\hline \multicolumn{7}{|c|}{ Group 3: Other (residual hypertropia) } \\
\hline 15 & No & 16 & 18 & No & 7 & 7 \\
\hline 16 & No & 36 & 38 & No & 14 & 16 \\
\hline 17 & Yes & 5 & 15 & No & 3 & 7 \\
\hline MVD & & 19.00 & 23.67 & & 8.00 & 10.00 \\
\hline Total MVD & & 16.06 & 24.65 & & 7.35 & 6.66 \\
\hline
\end{tabular}

AHP, abnormal head posture; PCT, prism cover test (vertical component in prism dioptres); PP, primary position; Rev, reversal in direction; MVD, mean vertical deviation.

was seen in group 1, with MVD improving from 14.33 PD (SD 8.69) to 4.44 PD (SD 4.82) in primary position and from 25.56 PD (SD 7.88) to 6.11 PD (SD 5.37) in downgaze.

Table 3 shows the Hess chart error scores (10 patients) and BSV scores (8 patients) that were recorded pre- and post-operatively. The pre-operative average score of BSV was $42 \%$, increasing to $62 \%$ post-operatively. The Hess chart error scores improved on average from 848.8 preoperatively to 296.4 post-operatively.
Patient 14 was affected by an unusual third nerve palsy of unknown origin with isolated and marked left inferior rectus and left medial rectus palsy. In primary position this patient had 40 PD of left esotropia along with 40 PD of left hypertropia. Therefore the inverse Knapp procedure was combined with a recess/resect procedure of the ipsilateral horizontal recti and a recession of the contralateral inferior rectus on adjustable suture. Therefore the effect of the inverse Knapp procedure in this case was difficult to assess. Overall,

Table 3. Pre- and post-operative Hess and BSV scores

\begin{tabular}{|c|c|c|c|c|}
\hline \multirow[b]{2}{*}{ Patient no. } & \multicolumn{2}{|c|}{ Pre-operative } & \multicolumn{2}{|c|}{ Post-operative } \\
\hline & Hess score & BSV score & Hess score & BSV score \\
\hline \multicolumn{5}{|c|}{ Group 1: Orbital trauma } \\
\hline 1 & 332 & 26 & 231 & 35 \\
\hline 2 & 1133 & & 561 & \\
\hline 3 & 362 & 34 & 60 & 39 \\
\hline 5 & 1271 & 10 & 322 & 31 \\
\hline 6 & 1389 & & 429 & \\
\hline 7 & 626 & 5 & 361 & 37 \\
\hline 9 & 354 & 38 & 240 & 45 \\
\hline \multicolumn{5}{|c|}{ Group 2: Inferior rectus underaction } \\
\hline 12 & 754 & 35 & 113 & 44 \\
\hline 13 & 1627 & 20 & 373 & 28 \\
\hline \multicolumn{5}{|c|}{ Group 3: Other } \\
\hline 16 & 640 & 30 & 274 & 32 \\
\hline Total & 8488 & 198 & 2964 & 291 \\
\hline Average & 848.8 & $24.75(42 \%)$ & 296.4 & $36.375(62 \%)$ \\
\hline
\end{tabular}

Maximum BSV score is 59 (100\%); 'best' Hess chart error score is 0. 
Table 4. Secondary procedures

\begin{tabular}{ll}
\hline Patient no. & Operations \\
\hline Undercorrections & \\
2 & R IR Faden \\
8 & L IR recession \\
12 & R IR recession \\
14 & R SO recession + IR Faden \\
17 & L SO posterior tenotomy \\
Overcorrections & \\
9 & L IO recession + R IR recession \& Faden \\
10 & Inverse Knapp revision \\
11 & R IR recession \\
\hline
\end{tabular}

$\mathrm{L}$, left; $\mathrm{R}$, right; $\mathrm{IR}$, inferior rectus; $\mathrm{SO}$, superior oblique; $\mathrm{IO}$, inferior oblique.

further operations were required for undercorrection in 5 cases (patients 2, 8, 12,14,17) and overcorrection in 3 cases (patients 9, 10,11) (Table 4). We found a marked subjective and objective improvement in the abnormal head posture. We did not find induced horizontal deviations or significant side-effects. In half our patients there was a slight, clinically insignificant reduction in the elevation of the operated eye detectable on the Hess chart. No patient complained of upgaze diplopia. Five patients continued to show some improvement in the field of BSV up to 4 months after the operation. No patient experienced a decrease in effectiveness with time for the duration of follow-up. There were no intraoperative complications.

\section{Discussion}

Other authors have reported a good mean vertical correction in primary position with the Knapp procedure $^{7,12}$ but they had small series and fewer heterogeneous primary diagnoses than this study. In this study, the inverse Knapp procedure proved to be effective in most cases. Both the Hess chart error scores and BSV scores, where available, were markedly improved. We also noted a marked subjective and objective improvement in the abnormal head posture.

It has been proposed that the degree of inferior rectus palsy may influence the effectiveness of the inverse Knapp procedure. ${ }^{8}$ Denning et al. ${ }^{8}$ suggested that the inverse Knapp procedure is effective for inferior rectus weakness of various degrees, since in their series the procedure had a greater effect in larger deviation and a lesser effect in smaller deviation. They concluded that the degree of inferior rectus palsy might determine the efficacy of the procedure. In our series the results do not appear to support this observation, with 3 patients requiring further surgery for overcorrection. Patients 10 and 11 were children with a diagnosis of inferior rectus weakness probably congenital in origin. They both had a markedly abnormal head posture and positive stereopsis. Patient 9 was an adult with an inferior rectus palsy following a road traffic accident without direct orbital trauma, in whom previous contralateral inferior rectus fadenisation had been unsuccessful. Review of their records suggests these patients might have had a partial weakness of the inferior rectus and this could explain the overcorrection. In these cases, either a recess/resect or a graded inverse Knapp procedure might have avoided the overcorrection and therefore may have been more successful. We favour transposition in most cases because of the risk of post-operative lid malposition when vertical recti are operated on. The extent of transfer is based purely on the surgeon's experience since there is no unequivocal guideline in the literature on the effect of graded versus full transfer of the horizontal recti.

The procedure has been applied to cases of marked inferior rectus weakness with negative traction test. von Noorden et al. ${ }^{9}$ used inferior rectus resection with or without recession of its antagonist to successfully treat isolated inferior rectus paralysis without mechanical restriction. We agree that in partial palsy of the inferior rectus the simple resect/recess procedure may be the first choice but our results seem to suggest that the transposition procedure can be effective as well. For complete inferior rectus palsy transposition may be a better choice than a vertical recess/resect procedure for two reasons. First, if the muscle is completely paralysed its strength cannot be improved by resection. Secondly, the risk of lower lid malposition is marked following a resection of the inferior rectus. For partial inferior rectus palsy, in contrast, the muscle does have some residual function and therefore either a recess/resect procedure of the vertical recti or a graded inverse Knapp procedure can be successful. This approach based on the extent of the palsy (complete/partial) is analogous to the standard treatment of sixth nerve palsy. ${ }^{13}$

We have extended the indications of the inverse Knapp procedure since we have reported on the good outcome in patients with residual miscellaneous hypertropia and poor binocular function. In these cases the main indication for surgery is cosmetic. Four patients had undergone previous multiple horizontal and vertical muscles surgery. The choice of an inverse Knapp procedure was based on a positive history of previous unsuccessful vertical squint surgery and the absence of binocular function. All the patients were happy with the cosmetic result and none complained of diplopia. In this group the MVD at primary position improved from preto post-operatively. We believe that in selected cases of residual hypertropia the inverse Knapp procedure gives a good cosmetic outcome.

In conclusion, the inverse Knapp procedure is an uncommon but an extremely useful strabismus operation in selected cases. We recommend it for the treatment of marked inferior rectus weakness, congenital or acquired, for post-traumatic inferior rectus underaction with or without orbital blow-out fracture and for residual large hypertropia in patients with poor binocular function. The extent of inferior rectus underaction should be assessed very carefully to avoid overcorrection. 


\section{References}

1. Alvaro M. Simultaneous surgical correction of vertical and horizontal strabismus. Ophthalmologica 1950;120:91-7.

2. Knapp P. The surgical treatment of double-elevator palsy. Trans Am Ophthalmol Soc 1969;67:304-23.

3. Burke JP, Ruben JB, Scott WE. Vertical transposition of the horizontal recti (Knapp procedure) for the treatment of double elevator palsy: effectiveness and long term stability. Br J Ophthalmol 1992;76:734-8.

4. Cooper EL, Greenspan JA. Congenital absence of the inferior rectus muscle. Arch Ophthalmol 1971;86:451-4.

5. Dunlap EA. Vertical displacement of horizontal recti. In: Symposium on strabismus. St Louis: CV Mosby, 1971:307-29.

6. Lipton JR, Page AB, Lee JP. Management of diplopia on down-gaze following orbital trauma. Eye 1990;4:535-7.

7. Burke JP, Keech RV. Effectiveness of inferior transposition of the horizontal rectus muscles for acquired inferior rectus paresis. J Pediatr Ophthalmol Strabismus 1995;32:172-7.
8. Denning AM, Ansons AM, Spencer AL, Kranemann C. Does the degree of inferior rectus palsy influence the effectiveness of the inverse Knapp procedure? Trans Eur Strabismus Assoc 1997;24:97-102.

9. von Noorden GK, Hansell RH. Clinical characteristics and treatment of isolated inferior rectus paralysis. Ophthalmology 1991;98:253-7.

10. Woodruff G, O'Reilly C, Kraft SP. Functional scoring of the field of binocular single vision in patients with diplopia. Ophthalmology 1987;94:1554-61.

11. Aylward GW, McCarry B, Kousoulides L, Lee JP, Fells P. A scoring method for Hess charts. Eye 1992;6:659-61.

12. Metz HS. Saccades with limited downward gaze. Arch Ophthalmol 1980;98:2204-5.

13. Lee JP. Modern management of sixth nerve palsy. Aust NZ J Ophthalmol 1992;20:41-6. 